\title{
Functional Outcome of Locking Compression Plate in Neer's two-part, three-part, four-part Proximal Humerus Fractures
}

\author{
${ }^{1} \mathrm{G}$ Mahesh, ${ }^{2} \mathrm{KC}$ Kiran, ${ }^{3} \mathrm{KV}$ Ramesh, ${ }^{4}$ Roshan Kumar
}

\begin{abstract}
Introduction: Proximal fractures of the humerus account for about 4 to $5 \%$ of all fractures. They are the most common fractures in elderly population. Treatment of unstable, displaced, and comminuted fractures of the proximal humerus remains challenging.
\end{abstract}

Objectives: The present study is undertaken to evaluate the functional outcome of proximal humerus fractures treated by locking compression plate in 20 patients.

Materials and methods: Prospective study was done involving 20 adult patients with proximal humerus fractures admitted from October 2012 to December 2013 treated by open reduction and internal fixation (ORIF) with locking compression plate. The functional follow-up was done for a minimum period of 3 months and the patients were evaluated by Constant Murley scoring (CMS).

Results: In our series, the majority of the patients were middleaged males, with road traffic accidents (RTAs) being the most common cause of injury, involving 2-part, 3-part, and 4-part fractures of the proximal humerus. The fractures were united in 19 patients and 1 patient had avascular necrosis (AVN). Excellent results were seen in $15 \%$ of patients, good results in $55 \%$, moderate results in $15 \%$, and poor results in $15 \%$ according to CMS. There were $95 \%$ union rates, $5 \%$ of AVN, and no failures.

Conclusion: In conclusion, locking compression plate is an advantageous implant in proximal humerus fractures due to angular stability, particularly in comminuted fractures and in osteoporotic bones of elderly patients, which allows their early mobilization.

Keywords: Locking compression plate, Open reduction and internal fixation, Proximal humerus fractures, Proximal humerus internal locking system plate.

How to cite this article: Mahesh G, Kiran KC, Ramesh KV, Kumar R. Functional Outcome of Locking Compression Plate in Neer's two-part, three-part, four-part Proximal Humerus Fractures. J Med Sci 2016;2(1):1-8.

Source of support: Nil

Conflict of interest: None

\footnotetext{
${ }^{1}$ Assistant Professor, ${ }^{2,3}$ Professor, ${ }^{4}$ Professor and Head

${ }^{1-4}$ Department of Orthopedics, RajaRajeswari Medical College and Hospital, Bengaluru, Karnataka, India

Corresponding Author: KC Kiran, Professor, Department of Orthopedics, RajaRajeswari Medical College and Hospital Bengaluru, Karnataka, India, e-mail: drkirankc@gmail.com
}

\section{INTRODUCTION}

Proximal humerus fractures are one of the most common fractures occurring in the human body. They account for approximately 4 to $5 \%$ of all fractures. ${ }^{1-3}$ They can cause great morbidity. It is a challenge to treat unstable, displaced, and comminuted fractures of the proximal humerus. Conservative management may result in nonunion, malunion, and avascular necrosis (AVN), which may lead to pain and dysfunction. ${ }^{4}$ Proximal humerus fracture management is constantly evolving, because of improved understanding of fracture characteristics and also various modifications and innovations in surgical techniques. ${ }^{5}$ Wide variety of treatments like percutaneous fixation, closed reduction, internal fixation, k-wire fixation, hemiarthroplasty, and recently use of locking compression plate have been advocated. Advantage of the locking compression plate is better anchorage of screws in osteoporotic bone. Because of the good fixation, enhanced stability will allow for early mobilization of the injured shoulder. More current data, concerning the use of locking plates in the treatment of fractures of the proximal humerus, have been very encouraging. ${ }^{6-8}$ There is ongoing controversy regarding the ideal methods of treating displaced proximal humerus fractures. Many published series in the literature are retrospective reviews of limited numbers of cases, with combined approaches and techniques used by different surgeons. They are still unsolved fractures in many ways. ${ }^{9-12}$

A recent meta-analysis by Bhandari et al concluded saying that "there was insufficient evidence to determine the optimal treatment for patients with displaced fractures of the proximal humerus." ${ }^{\prime 12}$

We conducted this study to assess and analyze fractures of the proximal humerus that were treated with the locking compression plate. We also assessed their clinical and functional outcome.

\section{MATERIALS AND METHODS}

A total of 20 patients with fractures of proximal humerus were treated surgically with proximal humerus internal locking system (PHILOS) plate between August 2012 and December 2013 and were followed for 3 months. We obtained institutional ethical committee's approval. 
A total of 20 cases were studied without following any conventional sampling procedure. All were operated with deltopectoral approach.

Patients with closed displaced 2-part, 3-part, 4-part proximal humeral fractures, acute fractures, age above 18 and also fit for surgery were recruited for the study. Patients with associated humerus shaft fractures, associated neurovascular injury, acute infection, pathological fractures, and old fractures were excluded from the study.

The patients were posted for surgery after routine investigation, preanesthetic check, and written informed consent for anesthesia and surgery. On patient arrival, $\mathrm{X}$-ray of proximal humerus, both anteroposterior view and axillary views, was taken, and fractures were classified according to Neer's classification. Surgery was started using an anterior deltopectoral approach for exposure of all the fracture sites. Postoperatively, all patients were immobilized in arm pouch with cuff and collar sling. Intravenous antibiotics was given for 5 days. Immediate postoperative $X$-rays were taken to assess the alignment of bone and maintenance of the optimal reduction. We also verified the implant impingement. Pendular exercises and assisted and passive active movements were started from the third postoperative day. Rotation exercises were started after 3 weeks. Eccentric strengthening exercises and resistive strengthening were begun after fracture union was confirmed after 10 to 12 weeks. The functional outcome was assessed according to Constant Murley scoring (CMS) system at 3 months.

\section{RESULTS}

Majority of the patients in our group were middle aged as it is the most active and working group of the population in general. The average age of the patients was 42.5 years (Table 1 ).

\section{Sex Ratio}

Further, as with other studies, our study showed a higher incidence of fractures in men than in women. The gender ratio was 19:1. This higher ratio can be explained by a higher involvement of males in day-to-day physical activities compared with females (Table 2).
Table 1: Patient demographics by age

\begin{tabular}{lll}
\hline$n$ & Average age (range) in years & Average age (mean) in years \\
\hline 25 & $24-60$ & 42.5
\end{tabular}

Table 2: Sex ratio in number (\%)

\begin{tabular}{lll}
\hline$n$ & Sex - Females & Sex - Males \\
\hline 25 & $1(5 \%)$ & $19(95 \%)$ \\
\hline
\end{tabular}

Table 3: Mode of injury: Number (\%)

\begin{tabular}{lll}
\hline$n$ & RTAs & Falls \\
\hline 20 & $17(85 \%)$ & $3(15 \%)$ \\
\hline
\end{tabular}

Major cause of fracture in our study was road traffic accidents (RTAs) in 17 cases (85\%), and in 3 cases (15\%), the mode of injury was falls (Table 3 ).

\section{Complications}

One patient had (5\%) AVN, two patients had (10\%) impingement, and two patients had (10\%) stiffness (Table 4).

The final results are graded according to CMS (Table 5). We had good to excellent results in 15 (75\%) patients treated in our institution. Patients with excellent and satisfactory scores had normal muscle function and functional range of motion according to CMS (Figs 1 to 3 ).

We had moderate and poor results in five $(25 \%)$ patients, out of which two patients had plate impingement who had restriction of abduction beyond $90^{\circ}$. Two patients had stiffness with restriction of movements and with persistent mild to moderate pain. Of the two patients, one had 2-part fracture with axillary artery rupture, which was repaired with fracture fixation; limb survived with stiffness and mild pain. All fractures got united in 3 months time. We had one case of AVN in our study (Fig. 4) who was advised hemireplacement.

\section{DISCUSSION}

The incidence of proximal humerus fractures has increased due to modern lifestyle changes and everincreasing number of RTAs when compared with the previous decade. Treatment options for complex proximal humerus fractures are restricted to T-buttress plates, K-wires, and bent ST-plates. Even if the injury is thoroughly analyzed and the literature is understood,

Table 4: Complications: Number (\%)

\begin{tabular}{llllllllll}
\hline Author & Year & Cases $n$ & Infection & Malunion & AVN & Impinge & Stiff & Screw penetration & Implant loose \\
\hline Our study & 2012 & 20 & - & - & $1(5 \%)$ & $2(10 \%)$ & $2(10 \%)$ & - & \\
\hline
\end{tabular}

Table 5: Constant Murley scoring

\begin{tabular}{lllll}
\hline CMS & Excellent \% & Good \% & Moderate \% & Poor \% \\
\hline Our study & 15 & 60 & 20 & 5 \\
\hline
\end{tabular}




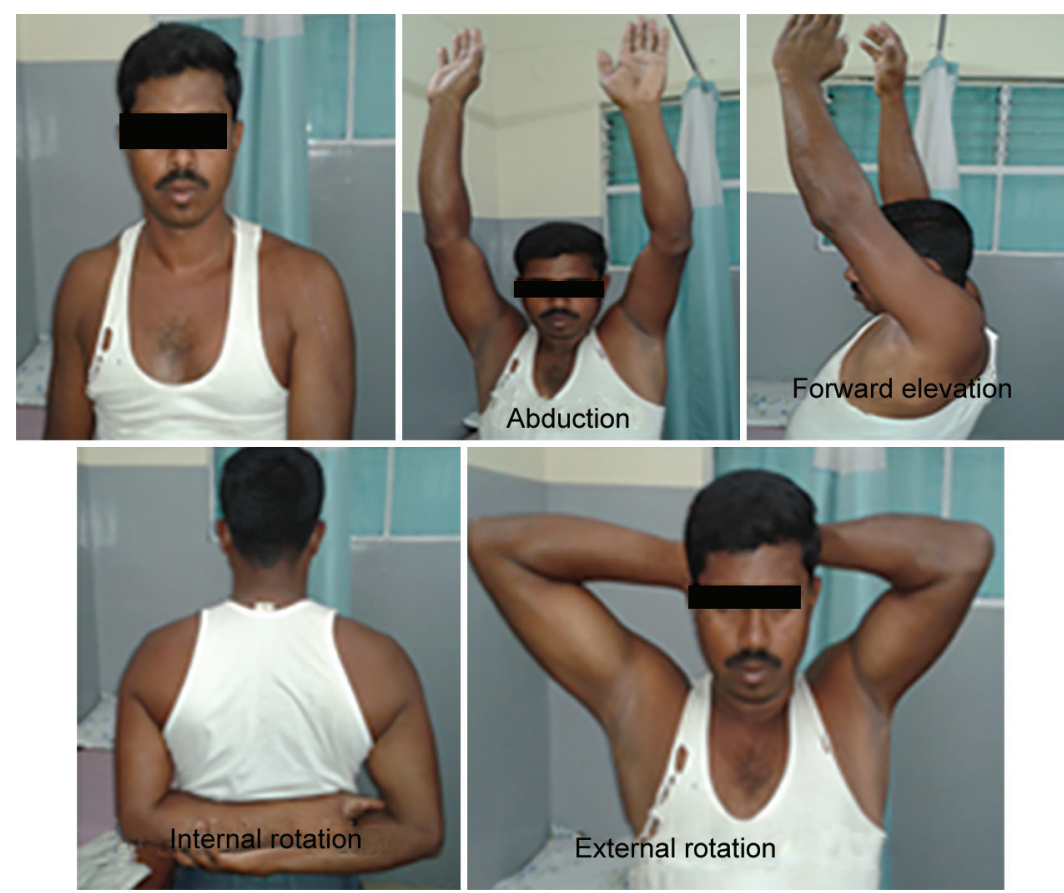

Fig. 1: Clinical illustration



Preoperative

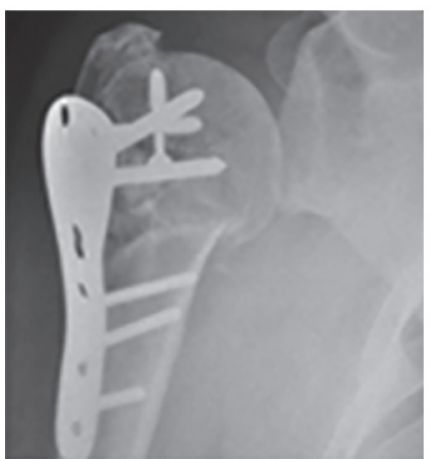

3 months



1st postoperative

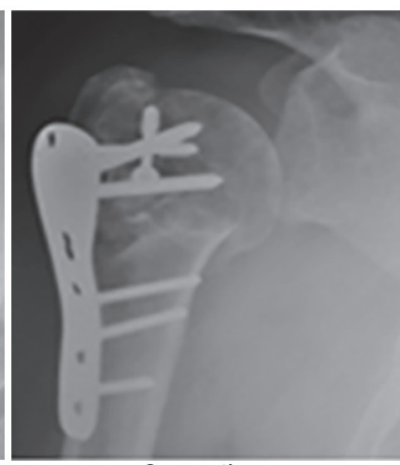

6 months

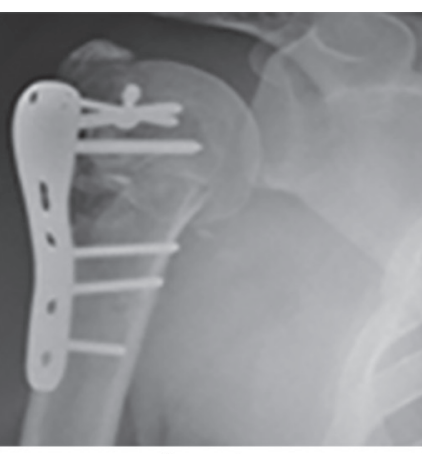

6 weeks

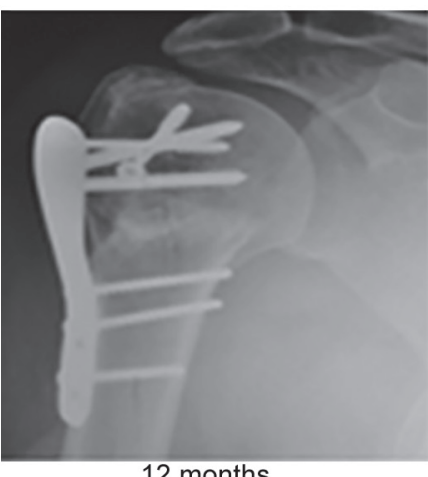

12 months

Fig. 2: Follow-up X-rays of patient 1

treatment and fixation of these displaced fractures or fracture with dislocation is extremely difficult.

The appropriate type of treatment, either operative or nonoperative in the elderly, low-demand patient, also remains unsolved. ${ }^{8}$

Locked plate techniques have become very popular and are being used to treat the open reduction and internal fixation (ORIF) of displaced fractures of the proximal humerus. ${ }^{5-9}$ Recent meta-analysis of the literature was unable to detect a clear advantage from internal fixation or arthroplasty for treatment of such complex fractures of the humerus. ${ }^{12}$ Most of the proximal humerus fractures which are undisplaced can be treated conservatively. Many studies have shown that the displaced fractures of the proximal humerus have a poor functional outcome when not treated because of severe displacement of fragments. ${ }^{13-17}$ 


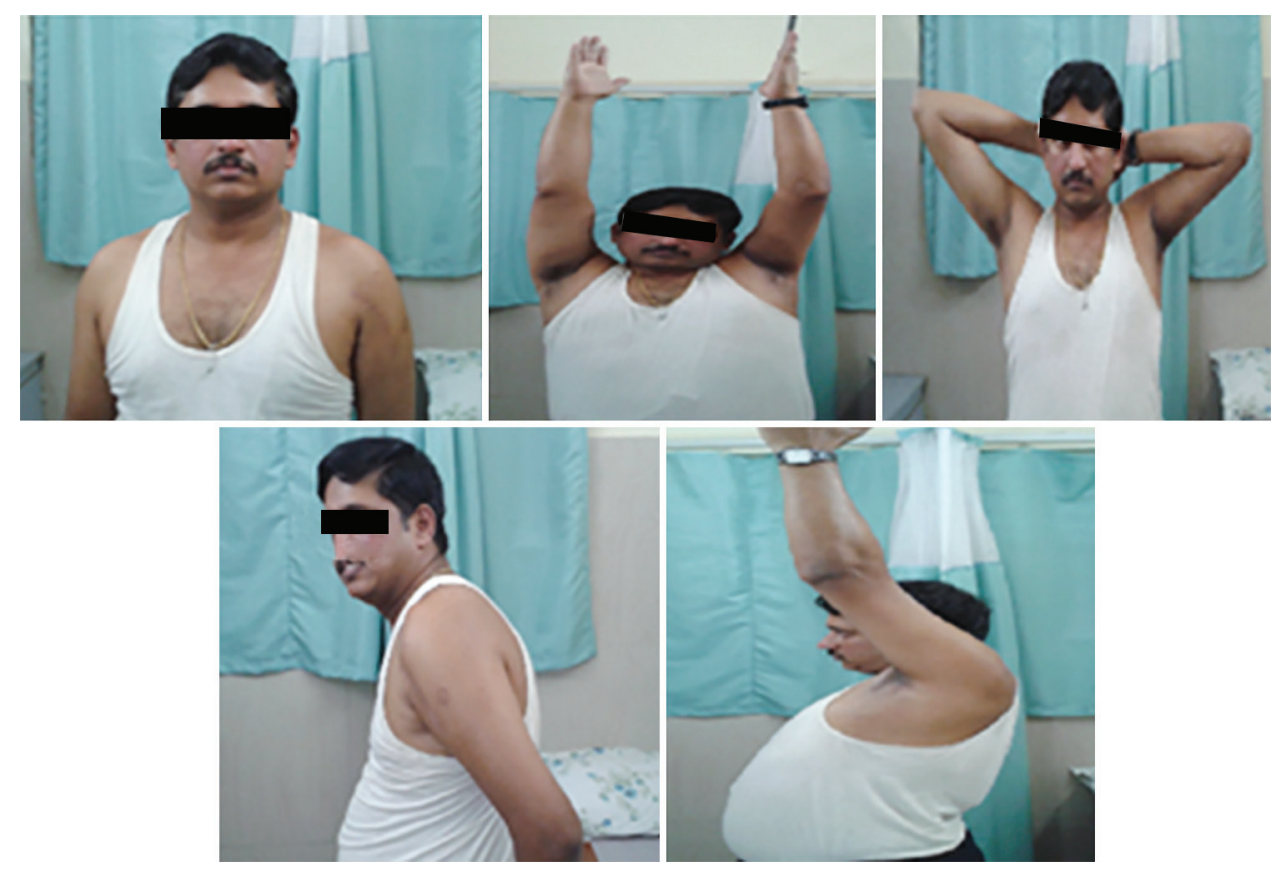



Preoperative

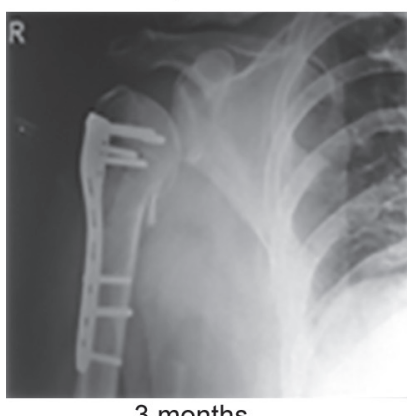

3 months



1 pod

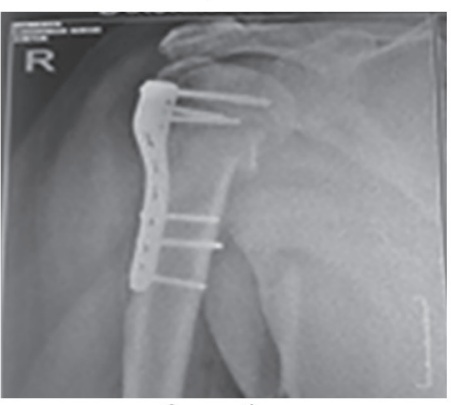

6 months

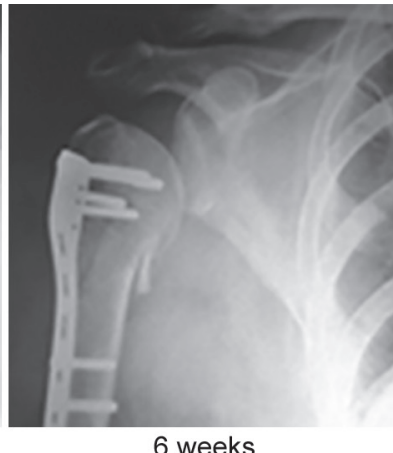

6 weeks



12 months

Fig. 3: Patient 2

However, the best management in these injuries is still uncertain and debatable. ${ }^{18}$ Hatzidaki et al studied the outcomes of 38 patients who were treated with locked angular-stable intramedullary implant fixation for 2-part surgical neck fractures. He did a follow-up for a minimum period of 12 months. All fractures healed primarily. The mean Constant score was 71, which was a mean age-adjusted Constant score of $97 \%$. In their study, patients could do an average forward elevation of $132^{\circ}$ and Constant pain score was $13(15=$ no pain). In their results, $37(97 \%)$ of 38 patients had satisfactory score. Only four patients $(11 \%)$ were reoperated. ${ }^{18}$
However, with the aim of getting anatomically accurate reductions, rapid healing, and early restoration of function, which is a demand of today's life, ORIF is the preferred modality of treatment. This goal is well achieved by locking compression plate as depicted in our study though data are small. The ideal treatment of complex fractures of the proximal humerus ${ }^{2,19,20}$ is still being debated and controversial. The fracture classification systems are prone to lots of errors. None of these give a clear prognosis and innovations for further outcome and treatment. Treatment of such fractures have resulted in satisfactory outcome by adopting ORIF techniqus. ${ }^{8,21-23}$ 


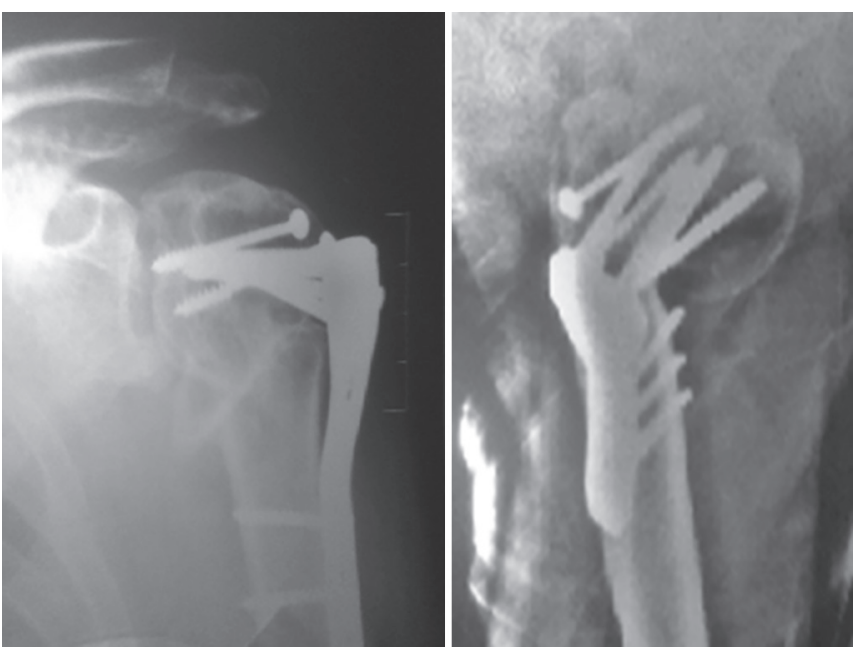

Fig. 4: Avascular necrosis

If the fractures are well reduced and stabilized until healing has occurred, it will usually end up with satisfactory results. This depends on the type of fracture, the quality of the bone, and the technique of reduction and fixation. The experience and skill of the surgeon also count.

We compared the CMS of our study with others. Good results of our study were comparable with the studies of Jan Magnus ${ }^{8}$ and Ramchander Siwach ${ }^{25}$ (Table 6).

We had satisfactory to excellent results in $15(75 \%)$ patients treated in our institution. All patients with excellent results and satisfactory results had normal muscular function and movement according to CMS.

We had moderate and poor results in five (25\%) patients, out of which two patients had plate impingement with restriction of abduction beyond $90^{\circ}$. Two patients had stiffness with restriction of movements and with persistent pain of mild to moderate degree. Of the two patients, one had 2-part fracture with axillary artery rupture, which was repaired with fracture fixation; limb survived with stiffness and mild pain. All fractures got united in 3 months. There was one case of AVN in our study, who was advised hemireplacement.

Our study is in agreement with other studies, with more than $75 \%$ patients having excellent to satisfactory results. ${ }^{14,15,26,27}$

A randomized controlled trial evaluated the results for a period of 2 years in which locking plate fixation $v s$ nonoperative treatment in elderly patients treated for a displaced 3-part fracture of the proximal humerus was studied. In this study, treatment with a locking plate

Table 6: Outcome of surgery (\%)

\begin{tabular}{lllll}
\hline CMS & Excellent \% & Good \% & Moderate \% & Poor \% \\
\hline Aggarwal $^{24}$ & 17.02 & 38.3 & 34.4 & 10.64 \\
Siwach et $\mathrm{al}^{25}$ & 28 & 64 & 8 & 0 \\
Bjorkenheim et $\mathrm{al}^{8}$ & 5.5 & 44.4 & 43 & 6.9 \\
Our study & 15 & 55 & 15 & 10 \\
\hline
\end{tabular}

resulted in superior functional outcome and health-related quality of life compared with nonoperative treatment. However, $30 \%$ of the patients studied required additional surgery because of fracture complications. ${ }^{26}$ It is important to note that the Constant score, the Disabilities of the Arm, Shoulder, and Hand (DASH) score, and the EQ-5D (EuroQol Group; Rotterdam, the Netherlands) score noted in the study were all superior in the locking plate group on all follow-up occasions. Even though the results were encouraging, it did not reach statistical significance. ${ }^{26}$

Sudkamp et $\mathrm{al}^{6}$ evaluated the complication rate and functional outcome of 187 patients after ORIF of proximal humerus fractures using a locking proximal humerus plate. At 12 months follow-up, in the study group, average Constant score was 70.6 , which was $85 \%$ of the contralateral side. The average active elevation was $132^{\circ}$ and the external rotation of the limb was $45^{\circ}$. The overall complication rate was $34 \%$ (52 of 155), and the common complication (21 of 155) was intraoperative screw penetration into the humeral head. Twenty-nine of these patients $(19 \%)$ required a reoperation.

In the study by Bahrs et $\mathrm{al}^{28}$ the Constant score and radiographic outcome in 66 patients with minimally displaced and/or impacted fractures of the proximal humerus treated with early immobilization were assessed. The fractures healed well, without nonunion, in all their patients. Imaging studies showed fracture displacement of less than $15^{\circ}$ of angulation and/or less than 5-mm displacement of the greater tuberosity in $80 \%$ of their patients.

They also found a significant association between the final Constant score, age, $\mathrm{AO}$ classification, and original fracture displacement. ${ }^{29}$ They concluded by saying that, earlier physiotherapy with a limited period of immobilization is sufficient in managing minimally displaced and/or impacted fractures of the proximal humerus.

In our study, use of proximal humerus locking compression plate resulted in favorable outcome in fractures of the humerus with displacement. Sound union was achieved in all patients. There was no incidence of implant failure which required reoperation. This locking compression plate has the advantage of locking head screws, which enter the head of the humerus at different angles.

We had unsatisfactory results in five (25\%) patients. Two patients had plate impingement with the restriction of abduction movement beyond an angle of $90^{\circ}$. Impingement of plate to acromion proximally results in limitation of abduction movement beyond $90^{\circ}$.

Two patients had unsatisfactory results with stiffness, restriction of movements, and mild to moderate pain. One patient had AVN. Regular follow-up and compliance was poor in these patients. In our study, none of the cases had implant failure. Our study has similar results compared with other studies of surgical management of the proximal humerus. ${ }^{25,30-36}$ 


\begin{tabular}{|c|c|c|c|c|c|}
\hline \multicolumn{3}{|c|}{ Table 7: Age incidence comparison } & \multicolumn{3}{|c|}{ Table 8: Sex incidence comparison } \\
\hline \multirow[b]{2}{*}{ Study } & \multirow{2}{*}{$\begin{array}{l}\text { Age of patient } \\
\text { (range), years }\end{array}$} & \multirow{2}{*}{$\begin{array}{l}\text { Average age } \\
\text { (mean), years }\end{array}$} & Study & Males & Females \\
\hline & & & Our study & 19 & 1 \\
\hline Gerber et $\mathrm{al}^{21}$ & $16-73$ & 44.9 & & & \\
\hline Fazal and Haddad ${ }^{34}$ & $22-85$ & 56 & \multicolumn{3}{|c|}{ Table 9: Mode of injury incidence comparison } \\
\hline Aggarwal et al ${ }^{24}$ & $23-81$ & 58.1 & Study & $R T A$ & Falls \\
\hline \multirow[t]{3}{*}{ Our study } & $24-60$ & 42.5 & Fazal and Haddad ${ }^{34}$ & 6 & 21 \\
\hline & & & Resch et al ${ }^{35}$ & 24 & 3 \\
\hline & & & Our study & 17 & 3 \\
\hline
\end{tabular}

Table 11: Complications after surgery; comparison with other studies

\begin{tabular}{|c|c|c|c|c|c|c|c|c|c|}
\hline Authors & Year & Cases & Infection & Malunion & AVN & Impinge & Stiff & $\begin{array}{l}\text { Screw } \\
\text { penetration }\end{array}$ & $\begin{array}{l}\text { Implant } \\
\text { loose }\end{array}$ \\
\hline Siwach et $\mathrm{al}^{25}$ & 2008 & 25 & & $8 \%$ & & $8 \%$ & $6 \%$ & & $4 \%$ \\
\hline Brunner et al $^{7}$ & 2009 & 157 & $1.26 \%$ & $2.53 \%$ & $8.22 \%$ & $2.53 \%$ & $2.53 \%$ & $13.9 \%$ & $3.16 \%$ \\
\hline Sharafeldin et $\mathrm{al}^{33}$ & 2008 & 27 & & & & & & & $3.7 \%$ \\
\hline Aggarwal $^{24,34}$ & 2010 & 56 & $3.5 \%$ & & & $1.8 \%$ & & & $3.5 \%$ \\
\hline Our study & 2012 & 20 & & & $1(5 \%)$ & $1(5 \%)$ & $2(10 \%)$ & & \\
\hline
\end{tabular}

Proximal humerus fractures occur more commonly in the middle age group. Numerous age-related studies point toward this, and our study is consistent with this finding. In our study, majority of the patients, i.e., $7(35 \%)$, were from age group of 41 to 50 years followed by 5 patients $(25 \%)>50$ to 60 years. The average age of the patients were 42.5 years (Table 7). Majority of the patients in our group are middle aged probably as it is the most active and working group of the population in general.

Further, as with other studies, our study showed a higher incidence of fractures in men than in women. The gender ratio was 19:1 (Table 8). This higher ratio can be explained by a higher involvement of males and the nature of work they do in day-to-day activities of life compared with females.

\section{Mode of Injury}

Major cause of fracture in our study was RTA in 17 cases $(85 \%)$, and in 3 cases $(15 \%)$ the mode of injury was falls (Table 9). Fazal and Haddad in their study have reported 21 cases $(77.8 \%)$ of fall and 6 cases $(22.2 \%)$ of RTA. Aggarwal et al in their study of 47 patients of proximal humerus fracture accounted for $55 \%$ of fracture, RTA $42.5 \%$ and 1 fracture $(2.5 \%)$ caused by seizure. In the study of Resch et al of 27 patients with 3-part and 4-part fracture, 24 patients had history of high-energy trauma.

Complications of our study with others are compared in Table 10. Avascular necrosis impingement was comparable with the study of Siwach ${ }^{29}$ and stiffness with Aggarwal's study.

CMS was compared with other studies.

Good results of our study were comparable with the studies of Bjorkenheim and Siwach (Table 11).
Table 12: Constant Murley scoring compared with other studies

\begin{tabular}{|c|c|c|c|c|}
\hline CMS & Excellent & Good & Moderate & Poor \\
\hline Aggarwal $^{3,24}$ & 17.02 & 38.3 & 34.4 & 10.64 \\
\hline Siwach et $\mathrm{al}^{25,27}$ & 28 & 64 & 8 & 0 \\
\hline Bjorkenheim et $\mathrm{al}^{8}$ & 5.5 & 44.4 & 43 & 6.9 \\
\hline Our study & 15 & 55 & 15 & 15 \\
\hline
\end{tabular}

Not many studies have been done on this topic in Indian patients with a medium sample size. Akanchha et al did a study on PHILOS plating but used a different score, and Siwach et al had a small sample size. ${ }^{37}$ We had only one case of AVN of humeral head in PHILOS group, which was asymptomatic clinically $(5 \%)$. It is much less than 6 to $10 \%$. As we did not obtain magnetic resonance imaging routinely, the true prevalence of AVN and other complications may be difficult to assess. ${ }^{37}$

\section{DRAWBACK}

Major limitation of our study is smaller sample size, short follow-up period, and relatively costly PHILOS plate compared with conventional plates. Further research in the field is needed to evaluate long-term effectiveness, rate of complications, and safety profile.

\section{CONCLUSION}

The present study was done to evaluate functional outcome and complication following surgical management of proximal humerus fracture by locking compression plate.

Locking compression plate is an advantageous implant in fixing proximal comminuted and displaced fractures of the humerus. It is also useful in osteoporotic bones of the elderly patients. It allows early mobilization. Further randomized trials are the need of the hour to 
compare the outcome of conservative nonoperative treatment with other surgical treatment options like ORIF and hemiarthoplasty.

\section{ACKNOWLEDGMENT}

Authors heartily would like to thank Dr H. Sahajanand for helping us in preparing this manuscript.

\section{REFERENCES}

1. Helmy N, Hinterman B. New trends in treatment of proximal humerus fractures. Clin Orthop Relat Res 2006 Jan;442: 100-108.

2. Baron JA, Barrett JA, Karagas MR. The epidemiology of peripheral fractures. Bone 1996 Mar;18(Suppl 3):209S-213S.

3. Court-Brown CM, Caesar B. Epidemiology of adult fractures. Injury 2006 Aug;37(8):691-697.

4. Zyto K. Non-operative treatment of comminuted fractures of the proximal humerus in elderly patients. Injury 1998 Jun;29(5):349-352.

5. Wijgman AJ, Rookler W, Patt TW, Raaymakers EL, Marti RK. Open reduction and internal fixation of three and four-part fractures of the proximal humerus. J Bone Joint Surg Am 2002 Nov;84(11):1920-1925.

6. Sudkamp N, Bayer J, Hepp P, Voigt C, Oestern H, Kääb M, Luo C, Plecko M, Wendt K, Köstler W. Open reduction and internal fixation of proximal humerus fractures with the use of the locking proximal humerus plate. J Bone Joint Surg Am 2009 Jun;91(6):1320-1328.

7. Brunner F, Sommer C, Bahrs C, Heuwinkel R, Hafner C, Rillmann P, Kohut G, Ekelund A, Muller M, Audigé L, et al. Open reduction and internal fixation of proximal humerus fractures using proximal humeral locked plate: a prospective multicenter analysis. J Orthop Trauma 2009 Mar;23(3):163-172.

8. Bjorkenheim JM, Pajarinen J, Savolainen V. Internal fixation of proximal humeral fractures with a locking compression plate. Acta Orthop Scand 2004 Dec;75(6):741-745.

9. Agudelo J, Schurman M, Stahel P, Helwig P, Morgan SJ, Zechel W, Bahrs C, Parekh A, Ziran B, Williams A, et al. Analysis of efficacy and failure in proximal humerus fractures treated with locking plates. J Orthop Trauma 2007 Nov-Dec;21(10):676-681.

10. Bastian J, Hertel R. Osteosynthesis and hemiarthroplasty of fractures of the proximal humerus: outcomes in a consecutive case series. J Shoulder Elbow Surg 2009 Mar-Apr;18(2): 216-219.

11. Solberg BD, Moon CN, Franco DP, Paiement GD. Locked plating of 3- and 4-part proximal humerus fractures in older patients: The effect of initial fracture pattern on outcome. J Orthop Trauma 2009 Feb;23(2):113-119.

12. Bhandari M, Matthys G, McKee MD. Four part fractures of the proximal humerus. J Orthop Trauma 2004 Feb;18(2): 126-127.

13. Depalma AF, Cautilli R. Fractures of the upper of the humerus. Clin Orthop 1971;20:73-93.

14. Neer II CS, Rockwood CA. Fractures and dislocations of the shoulder. In: Rockwood, C.A.; Green, D.P., editors. Fracture in adults. Philadelphia, PA: Lippincott; 1984. p. 675-721.
15. Williams GR, Wong KL. Two-part and three part fractures management of proximal and distal humerus fracture. Orthop Clin North Am 2000 Jan;31(1):1-21.

16. Powell, Scott E.; Chandler, Robert W. Fractures of the proximal humerus. In: Jobe, Frank W., editor. Operative techniques in upper extremity sports injuries. St. Louis, MO: Mosby; 1995. p. 313-340.

17. Zyto K. Non-operative treatment of comminuted fracture of proximal humerus in elderly patients. Injury 1998 Jun;29(5):349-352.

18. Hatzidakis AM, Shevlin MJ, Fenton DL, Curran-Everett D, Nowinski RJ, Fehringer EV. Angular-stable locked intramedullary nailing of two-part surgical neck fractures of the proximal part of the humerus. A multicenter retrospective observational study. J Bone Joint Surg Am 2011 Dec;93(23):2172-2179.

19. Hessmann M, Baumgaertel F, Gehling H, Klingelhoeffer I, Gotzen L. Plate fixation of proximal humerus fracture with indirect reduction; Surgical technique and results using the shoulder score. Injury 1999 Sep;30(7):453-462.

20. Hintermann B, Trouillier HH, Schufer D. Rigid internal fixation of fractures of the proximal humerus in older patients. J Bone Joint Surg Br 2000 Nov;82(8):1107-1112.

21. Gerber C, Worner CM, Vienne P. Internal fixation of complex fractures of the proximal humerus. J Bone Joint Surg Br 2004 Aug;86(60):848-855.

22. Charalambous CP, Siddiqe I. Proximal humerus internal locking for the treatment of proximal humerus fracture. Arch Orthop Trauma Surg 2007 Apr;127(3):205-210.

23. Babst $R$, Brunner $F$. Plating in proximal humeral fractures. Eur J Trauma Emerg Surg 2007 Aug:33(4):345-356.

24. Aggarwal S, Bali K, Dhillon MS, Kumar V, Mootha AK. Displaced proximal humeral fractures: an Indian experience with locking plate. J Orthop Surg Res 2010 Aug;5:60.

25. Siwach R, Singh R, Rohilla RK, Kadian VS, Sangwan SS, Dhanda M. Internal fixation of proximal humerus fracture by locking proximal humerus plate in elderly osteoporotic. J Orthop Traumatol 2008 Sep;9(3):149-153.

26. Owsley KC, Gorczyca JT. Fracture displacement and screw cutout after open reduction and locked plate fixation of proximal humeral fracture. J Bone Joint Surg Am 2008 Feb;90(2):233-240.

27. Koukakis A, Apostolou CD, Taneja T, Korres DS, Amini A. Fixation of proximal humerus fractures using the PHILOS plate. Clin Orthop Relat Res 2006 Jan;442:115-120.

28. Bahrs C, Rolauffs B, Dietz K, Eingartner C, Weise K. Clinical and radiological evaluation of minimally displaced proximal humeral fractures. Arch Orthop Trauma Surg 2010 May;130(5):673-679.

29. Hudak PL, Amadio PC, Bombardier C. Development of an upper extremity outcome measure: The DASH (Disabilities of the Arm, Shoulder, and Hand). The Upper Extremity Collaborative Group (UECG). Am J Ind Med 1996 Jun;29(6):602-608.

30. Moda SK, Chadha NS, Sangwan SS, Khurana DK, Dahiya AS, Siwach RC. Open reduction and fixation of proximal humeral fractures and fracture dislocations. J Bone Joint Surg Br 1990 Nov;72(6):1050-1052.

31. Szyszkowitz R, Seggl W, Schleifer P, Cundy PJ. Proximal humeral fractures: Management techniques and expected results. Clin Orthop Relat Res 1993 Jul;293:13-25.

32. Moonot P, Ashwood N, Hamlet M. Early results for treatment of three- and four-part fractures of the proximal humerus 
using the PHILOS plate system. J Bone Joint Surg Br 2007 Sep;89(9):1206-1209.

33. Sharafeldin KN, Quinlan JF, Corrigan J, Kelly IP. Functional follow-up of locking plate fixation of fractures of the proximal humerus. Eur J Orthop Surg Traumatol 2008 Feb;18(2): 87-92.

34. Fazal MA, Haddad FS. PHILOS plate fixation for displaced proximal humeral fractures. J Orthop Surg (Hong Kong) 2009 Apr;17(1):15-18.
35. Resch H, Povacz P, Frohlich R, Wambacher M. Percutaneous fixation of three and four part fractures of proximal humerus. J Bone Joint Surg Br 1997 Mar;79(2):295-300.

36. Martinez AA. Proximal humerus locking plate for proximal humerus fracture - Retrospective study. J Orthop Surg 2009;17(1):10-14.

37. Tiwari A, Sinha R, Johar M, Akanchha. Evaluation of Different Modalities of Osteosynthesis of Proximal Humerus Fractures in Adults. Ind J Orth Surg 2016;2(1):27-34. 